most satisfactory when circumstances are promising, holds out no justification for the encouragement of delusion, or the perpetration of impotent though dangerous measures, and should be checked, not pandered to, when circumstances are adverse and unpromising.

Let the effects of Wardrop's operation, as illustrated by Mr. Broadbent's case, be carefully analysed, and there cannot, I think, be any difference of opinion respecting it. It evi. dently did not exert the slightest sanative power over the disease, but permitted it to run its course unchecked, and to produce its fatal issue exactly as would have resulted without the operation. Any apparent mitigation of symptoms--such, for example, as the occasional absence of bruit-was manifestly due not so much to the operation as to other causes. Secondary hæmorrhage repeatedly occurred; digitalis was administered these much more reasonably explain the phenomena observed, which were construed into indications of amendment; and these effects could surely have been commanded more safely without the operation. Unclosed wound of the carotid, with its concomitant dangers and tortures, could but fearfully aggravate systemic disturbance, and tend, in all reasonable probability, to accelerate the event; it undoubtedly rendered the brief period of the unfortunate patient's existence all the more wretched.

Approval and justification of the operation are notwithstand. ing sought on the ground of the most satisfactory progress of the case for two months; the true meaning of which is, the man did not die within this period; and it is intimated that but for an unexpected attack of bronchitis the result might have been different. To this bronchitic attack is attributed probable displacement of some of the coagula within the sac, although, in the first part of the remarks, it is observed, "The large size of the tumour prevented my attempting to displace the coagula, if any existed, or of exciting new action in the sac by friction of its walls, the plan so ingeniously carried out some years ago by Mr. Fergusson."

By this we are led, as the extremely learned and original Brown-Séquard has pointed out, ${ }^{*}$ to two singularly contra. dictory series of inferences, which may be thus stated:-Dis. placement of the coagula within the sae is inimical to cure; and, Displacement of the coagula within the sac is favourable to cure: further proof that the surgical treatment of aneurism of the anonyma, in its present state, is based on nothing sound, and constitutes, in fact, but absurd and rash experimentalizing.

Surgery, in the present state of her resources, is inadequate to contend with aneurism of the anonyma, and it is culpable perversion of her high position to be pressed into such unholy service. Until something much more promising presents itself, the treatment of this serious malady pertains much more rationally and humanely to the department of Medicine.

Gorleston, Great Yarmouth, 1861.

\section{REMOVAL OF A NEEDLE FROM BENEATH THE SKIN OF THE ABDOMEN OF \\ A CHILD.}

BY GEORGE D. GIBB, M.D., M.R.C.P.

THE following case may appear to be trivial, but my object in recoraing it is to show the extreme carelessness of nurses in allowing very young children to play with pins and needles:-

A lady was superintending the ablution of several of her children in a bath. The youngest, a female child, not two years old, cried very much; it had been very fractious and irritable for several days. The cause of this was unsuspected until the mother discovered a loose body under the skin just below the right false ribs, which she thought might be a portion of a rib. The child evinced pain when it was touched. This was shown to me; and I had no difficulty in at once recognising a needle, although it felt as if there really was a larger body from the duplicature of integument around it. A minute speck was discernible upon the skin lower down, which was no doubt the point of ingress. No satisfactory explanation could be afforded of how the needle came there. As the children, however, had been permitted indiscriminately to play with pins and needles by the nurse, the solution of the question was easy enough. Next day I forced the point of the needle through the skin, and drew it out with a pair of forceps. It was nearly an inch and a half long, quite black, but not rusty. The child is now as lively as heretofore.

Portman-street, Portman-square, Oct. 1861

* The Lancet, July $6 \mathrm{th}, 150 \mathrm{I}, \mathrm{p} .4$.
REPORT OF A

\section{CASE OF POISONING BY STRYCHNIA.}

RECOVERY.

BY WM. TRAVERS, EsQ., M.P.C.S. ENG.

Dr. PART's able paper on "Poisoning by Strychnia," contained in The Lancer of March 30 th and April 6th last, has led me to believe that a brief notice of the following case may not prove uninteresting, analogous as it is in nearly every re. spect to Dr. Part's own case, the poison, too, having been taken in the same form, that of "Battle's vermin-killer."

Kate $\mathrm{W}-$, aged twenty, a married woman, a Greek by birth and extraction, was brought to Charing-cross Hospital at half-past eleven $P_{0} M_{\circ}$ on the 17 th of March last, having about an hour previously, in a fit of jealousy, swallowed the entire contents of a packet of the above-mentioned compound. She had been already visited by a surgeon, and an emetic had been administered, without however producing vomiting. Upon admission, the body was perfectly rigid; limbs extended and immovable; eyes protruding and fixed; teeth firmly clenched; countenance anxious, and of a dusky hue; breathing deep and irregular; pulse very small and quick. The spasm shortly relaxing, she became sensible for a few moments, only again to relapse very speedily into a similar state. Being anxious to remove without delay any of the poison remaining in the stomach, I attempted to use the stomach-pump; but finding on each trial to introduce the tube, or in fact on even touching the patient, that the spasm increased tenfold in violence, $I$ abstained from any further effort, and contented myself with forcing her to drink (though with great difficulty) a powerful emetic dose of sulphate of zinc dissolved in hot water. This fortunately soon took effect, and vomiting was kept up for upwards of half an hour. The tetanic spasms had, however, by this time increased very much in intensity, each attack commencing with a prolonged loud and peculiarly shrill scream; the body then becoming perfectly rigid, the legs widely separated, and opisthotonos occurring to such an extent that the patient appeared to rest almost solely on the occiput and heels. During the fit the dyspncea became more extreme, the eyes open to their widest extent, the eyeballs started from their sockets, and the pupils dilated to the utmost. At length, after the lapse of about half a minute, a sudden tremor appeared to seize the entire frame; the limbs became relaxed, the muscles flaccid, the eyes dim, the skin bedewed with a cold clammy perspiration, and the breathing scarcely perceptible; not any pulse was to be felt at the wrist; the patient, in fact, was lying as I believed dead. Ammonia applied to the nostrils and cold water dashed in the face gradually increased the force of the respiration, and the pulse could again be felt. But with the return to consciousness the symptoms of spasm were once more renewed, became more violent as the sensibility returned, and held out a prospect of becoming as formidable as before.

Doubting whether the patient wonld survive a second attack I was anxious, if possible, at once to restrain the spasm, and with this view determined to administer chloroform. This I proceeded to do at once, carefully watching the patient, yet at the same time so using it as to bring her as speedily as possible under its influence. Its effects were soon perceived; in a very short space of time the countenance lost its fixed and anxious appearance, the eyes became less prominent, the opisthotonos subsided, the limbs gradually became relaxed, the respiration more normal, the pulse fuller and less freruent, and, when completely under its influence, the spasm had entirely left her, and she lay as in a sound sleep. I now withdrew the inhaler, yet remained by her, and at each attempt at return to consciousness (generally showing itself by some spasmodic working of the features) I reapplied the chloroform. At length, two hours and a half having elapsed, and the pulse becoming weaker, whilst a slight return to sensibility not having been accompanied with any return of the spasm, I allowed the effects of the anæsthetic to pass off. In the course of half an hour, some slight convulsive attacks having again shown themselves and becoming gradually more violent, I gave the patient forty minims of the tincture of opium with half a drachm of the compound spirit of ammonia in camphor mixture; and at the end of an hour, the symptoms still occurring occasionally and the patient being somewhat excited and restless, I repeated the dose. Shortly after this she fell into a sound sleep, which continued, with scarcely an interval of waking, for six hours. The following morning she expressed herself as 
feeling quite well, only very weak, and occasionally complained of a pricking sensation in the extremities. Vomiting, which could with difficulty be allayed, now set in, without any assignable cause, leading Dr. Willshire (under whose care she was now placed) to suspect the presence of some irvitant poison besides strychnia in the compound she had taken. Upon subsequent inquiry, I found that the packet also contained a small quantity of arsenic, which might supply a reason for the otherwise unaccountable continued gastric irritation. Under treatment the vomiting was allayed, the nervous irritability which succeeded subsided, and the patient was discharged at the end of a few days quite convalescent.

Charing-cross Hospital, 1861.

\section{de cetirrot}

OF THE PRACTICE OF

\section{MEDICINE AND SURGERT IN THE}

\section{HOSPITALS OF LONDON.}

Nulla est alia pro certo noscendi via, nisi quam plurimss et morborum et dissectionum historias, tam aliorum proprias, collectas habere et inter se comparare.-Mongagni. De Sed. et Caus. Morb., lib. 14. Procemium.

\section{GUY'S HOSPITAL.}

NECROSTS OF THE CRICOID CARTILAGE, WITH SEVERE ATTACKS OF DYSPNOEA FROM PRESSURE ON THE RECURRENT LARYNGEAL NERVE; TRACHEOTOHY; FATAT RESULT.

(Under the care of Dr. PAVY.)

OF the various cartilages which enter into the construction of the larynx, the cricoid is considered to be more often the subject of disease than any of the others. It was the only part found affected in the following case; and, singularly enough, its lining of mucous membrane was not involved, nor was the passage through it in any way encroached upon. The dyspncea arose from another cause-namely, compression of the recurrent laryngeal nerve between some enlarged glands. The notes of the case were furnished by Mr. Harry Geo. Moore, clinical clerk.

James L—, aged thirty-one, sailor, admitted March 8th, 1861. Family all healthy. Had syphilis ten years ago. Two years since was under Dr. Rees in Luke ward with large sores in the legs, and ten months ago he was in Stephen ward with ulcerated sore-throat. Has been very much exposed to all kinds of weather. Very irregular in his living, having drunk a great deal. Three weeks back, when on board ship, he caught a severe cold; and about a week afterwards his throat became very bad, and he was told he had croup, having much difficulty in breathing, and feeling as if there was a heavy weight at his chest. He was blistered and leeched, which relieved the chest; but the throat still continued very bad, the patient being scarcely able to breathe, but not complaining of pain. On the 15th of March, before having the leeches and blisters applied, he suddenly fell down utterly exhausted, and suffering from excessive dyspncea, which lasted for about twelve hours. Since then he has had a similar attack four or five times. He was sent to the hospital, his case appearing perfectly hopeless to the physician attending him. Has no dysphagia.

State on antmission.-Dyspnœa excessive; breathing with a well-marked croupy sound; nothing abnormal to be seen about the throat, to which part he refers the greatest amount of un easiness; there is not the slightest pain on pressure; cannot lifdown at all, as he is nearly choked if he attempts to do so; tongue very white; bowels regular; bronchitic expectoration, slightly tinged with blood; a good deal of hoarseness of voice, and cough rather troublesome; the skin of the body is very clear, as also the sclerotic, and feels cold; pulse soft and compressible; glands on the left side of the neck, behind the sterno-mastoid muscle, enlarged. Ten leeches to be applied over the trachea, and to have a mixture of wine of antimony in julep of ammonia every four hours. To inhale steam frequentlys.
March 9th. - Very ill in the night, having had another attack of dyspnce ; but after inhaling steam he began to breathe better, and this morning seems much improved, and speaks. with a great deal more ease. Pulse 96 ; respirations 18.

11 th. - Breathes quite comfortably, but is not able to lie down at all, and the croupy noise still continues; takes food very well.

12th. - Breathing not quite so good as yesterday; respira. tions 22 ; pulse 90 ; has cough, the cause of which he refers to. the chest, but there is no disease to be found there by the imperfect examination the patient's weak state allows of being made. Ordered a blister to the sternum.

About seven o'clock P.M. he appeared to be sinking rapidly, and at nine tracheotomy was performed. He rallied for a little while, but at eleven he seemed to be choking, and died.

Post mortem examination. - Cricoid cartilage externally ul. cerated at the back part, small pieces of dead cartilage separating from the rest. The mucous membrane over the diseased parts seemed perfectly healthy. Slight bronchitis, and tubes filled with frothy blood. The recurrent laryngeal nerve was completely wedged in between some enlarged glands, just behind the lower part of the posterior border of the sterno. mastoid muscle.

\section{ST. GEORGE'S HOSPTTAL.}

TUBERCILOUS ABSCESS BURSTING INTO THE TRACHEA OF A CHILD; FATAT RESULT; AUTOPSY.

(Under the care of Dr. FuLder.)

THE symptoms which were present in the following case, two or three days before death, are clearly explained by the discovery of a large abscess which had ulcerated into the trachea. The fatal issue was not sudden, because the ulcerated opening was plugged by masses of crude tubercle.

The notes of the case were taken by Mr. Jones, one of the hospital pupils :-

Harriet B-, aged four years, was admitted on the 6 th of May, 1861. She was said to have suffered, more or less, ever since she was attacked with whooping-cough two years ago. This left a frequent hacking cough. About six weeks previous to her death her mother observed that her breathing was short and accompanied with wheezing, her cough was worse, her skin hot, and she complained of pain in the chest. Under medical treatment she appeared to get better; but three weeks afterwards she had a similar attack, likewise of a temporary character. On the 4th of May she was noticed to be hoarse, and was heard to wheeze in breathicg; but she was able to go out and play on this and the following day. On the 6th the cough increased, the breathing grew very difficult, and she was brought to the hospital. She was then in a state of considerable dyspnœa, with much movement of the alæ nasi. There was a (not very frequent) dry cough, with rattling of mucus in the larger tubes. The skin was cool; the lips natural in colour; the pulse quick and small; the tongue clean. An emetic was at once given, which acted freely, and cansed the ejection of some cheesy matter, which looked much like lymph. No relief was experienced. The dyspnoea continued to in. crease until early the next morning, when she died. The question of tracheotomy was not debated, as the case was not. regarded as one of croup.

A utopsy, eleven hours after death. - The body was in good condition. The fauces and pharyux were healthy. On cutting into the thorax, an abscess was seen just below the front of the sternum. This was found to proceed from the softening of a large collection of crude tubercle, which lay close upon the upper edge of the thymus gland, but did not seem to be deposited in that body. It had exercised considerable pressure upon the trachea, and had burst into that trabe, close above its bifurcation, by a large round opening, into which some of the crude tubercle was still projecting. The lining membrane of the trachea was slightly vascular. There was much crude tubercle in the bronchial glands, which appeared to render it probable that the oricinal seat of the tubercular abscess had been in one of the most anterior of those glands. Both lungs were studded throughout with miliary tubercle, otherwise they were healthy, and contained little fluid. The heart, liver, and spleen were healthy. The mesenteric glands were loaded with crude tubercle, forming large hard masses, like marbles. In the lower part of the small intestine was found a little scrofulous deposit, in the shape of small rounded tubercles, and a single cicatrix of an ulcer. 